Centro de Estudios Constitucionales de Chile Universidad de Talca

"La obligatoriedad del Estado venezolano en el sistema de fuentes y los argumentos

de la Sala Constitucional para inejecutar las sentencias de la Corte-IDH”

\title{
LA OBLIGATORIEDAD DEL ESTADO VENEZOLANO EN EL SISTEMA DE FUENTES Y LOS ARGUMENTOS DE LA SALA CONSTITUCIONAL PARA INEJECUTAR LAS SENTENCIAS DE LA CORTE-IDH*
}

THE COMPULSORY OF THE VENEZUELAN STATE

IN THE SOURCES SYSTEM AND THE ARGUMENTS OF THE CONSTITUTIONAL ROOM TO EXECUTE THE CORT SENTENCES

\author{
Fanny Patricia Niño HeRnández ${ }^{* *}$ \\ Universidad Francisco de Paula Santander \\ fannypatricianh@ufps.edu.co \\ July Andrea Mercado Duque ${ }^{* * *}$ \\ Universidad Francisco de Paula Santander \\ julyandreamd@ufps.edu.co \\ Mayra Alejandra Bohada Rojas * $^{* * *}$ \\ Universidad Francisco de Paula Santander \\ mayraalejandrabr@ufps.edu.co \\ RuSMARY RAMÍREZ BAYONA**** \\ Universidad Francisco de Paula Santander \\ rusmaryrb@ufps.edu.co
}

* Trabajo recibido el 7 de junio de 2016 y aprobado el 17 de mayo de 2017.

El presente artículo es producto del proyecto de investigación "Efectividad en la ejecución de las Sentencias de la Corte Interamericana de Derechos Humanos: Caso Venezuela” del Grupo de Investigación Jurídico, Comercial y Fronterizo, en asociación con el semillero de investigación John F. Kennedy de la Universidad Francisco de Paula Santander de la ciudad de Cúcuta-Colombia.

** Docente Universidad Francisco de Paula Santander-Cúcuta. Investigador miembro del Grupo de Investigación Jurídico, Comercial y Fronterizo. Especialista en Derecho Comercial de la Universidad Autónoma de Bucaramanga. Doctor en Derecho del Comercio y de la Contratación de la Universidad Autónoma de Barcelona-España.

${ }^{* * *}$ Estudiante de Derecho de la Universidad Francisco de Paula Santander-Cúcuta, miembro del semillero de investigación John F. Kennedy, adscrito al Grupo de Investigación Jurídico, Comercial y Fronterizo.

${ }^{* * * *}$ Estudiante de Derecho de la Universidad Francisco de Paula Santander-Cúcuta, miembro del semillero de investigación John F. Kennedy, adscrito al Grupo de Investigación Jurídico, Comercial y Fronterizo.

${ }^{* * * * *}$ Estudiante de Derecho de la Universidad Francisco de Paula Santander-Cúcuta, miembro del semillero de investigación John F. Kennedy, adscrito al Grupo de Investigación Jurídico, Comercial y Fronterizo. 
RESUMEN: La ejecución de sentencias proferidas por la Corte Interamericana de Derechos Humanos está en cabeza del Estado condenado, quien tiene la obligación de ejecutarlas de forma integral; sin embargo, la Sala Constitucional del Tribunal Supremo de Justicia de Venezuela ha declarado inejecutables algunas sentencias, argumentando la violación del ordenamiento jurídico interno y la vulneración de la soberanía nacional, desconociendo de esta forma las obligaciones que el Estado venezolano como firmante del Tratado asumió al adherirse al mismo.

ABSTRACT: The execution of the pronounced sentences by the Interamerican Human Rights Court, isat the head of the condemnedd state which has the duty of executing themon a whole way, nevertheless, the constitutional room of the Venezuelan Supreme Justice Court has declared unenforceable some sentences, arguing the violation of the internal legal order and the violation of the national sovereignty, not knowing in this way, the duties that the Venezuelan state as signatury of the treaty, assumed to adhere to it.

PALABRAS CLAVE: Sistema Interamericano, ejecución de sentencias, tratados internacionales, juez constitucional y efectividad.

KEYWORDS: Inter-American System, enforcement of judgments, International Treaties, Constitutional Court, effectiveness.

\section{INTRODUCCIÓN}

Como consecuencia de las constantes vulneraciones a los derechos ocurridas durante la Segunda Guerra Mundial, se crearon organismos internacionales con el fin de promover la observancia y defensa de los Derechos Humanos en todo el mundo. Estos Sistemas Regionales de Protección tienen en común no sólo un acuerdo internacional donde se plasma el objeto de protección, sino también un órgano jurisdiccional que emite sentencias condenatorias contra los Estados incumplidos. En el sistema interamericano, la Corte Interamericana de Derechos Humanos (en adelante, Corte IDH) ha sido dotada de jurisdicción transnacional mediante el artículo 62.3 ${ }^{1}$ de la Convención Americana de Derechos Humanos (en adelante, $\mathrm{CADH})$.

Entre los Estados cobijados por esta jurisdicción, se encuentra el Estado venezolano desde el año 1981, cuando ratificó la competencia contenciosa de la Corte. A partir de allí, se han emitido varias sentencias en su contra en las que el organismo internacional ha encontrado transgresiones notables del Tratado, sin embargo, algunas sentencias han sido desconocidas por la justicia venezolana.

1 "La Corte tiene competencia para conocer de cualquier caso relativo a la interpretación y aplicación de las disposiciones de esta Convención que le sea sometido, siempre que los Estados Partes en el caso hayan reconocido o reconozcan dicha competencia, ora por declaración especial, como se indica en los incisos anteriores, ora por convención especial" (Convención Americana de Derechos Humanos, 1969, artículo 62.3). 
El estudio del incumplimiento de los fallos de la Corte IDH resulta relevante no solamente por las consecuencias que para la protección de los derechos se susciten en Venezuela, sino porque puede ser una luz de alerta para la efectividad del sistema, ya que no ha sido dicho Estado el único que ha incumplido los fallos, existiendo un precedente en el caso Petruzzi y otros vs. Perú ${ }^{2}$ (1999) donde no se acata la decisión bajo el argumento que la Corte IDH incurrió "en un exceso en su competencia funcional al analizar la compatibilidad de leyes peruanas con la Convención" " A raíz de esta situación, Perú se apartó de la competencia contenciosa de este Tribunal transnacional.

Por todo lo anterior, se analizará la validez jurídica de los argumentos esgrimidos por la Sala Constitucional del Tribunal Supremo de Justicia Venezolano (en adelante, TSJ), al declarar inejecutables algunos de los fallos emitidos por la Corte IDH, se abordará la relación del Estado venezolano con el Tratado, la efectividad de las sentencias, los argumentos de la Sala Constitucional y la obligatoriedad de los compromisos adquiridos en la Convención Americana de Derechos Humanos.

\section{Venezuela y el Sistema Interamericano de Derechos Humanos}

El Estado venezolano, desde la creación de la Organización de Estados Americanos (en adelante OEA) en 1948, manifestó su interés por la defensa de los Derechos Humanos en el continente firmando la Declaración Americana, aprobada en la Novena Conferencia Internacional en Bogotá-Colombia (1948). Once años después, en la Quinta Reunión de Consulta de Ministros de Relaciones Exteriores celebrada en Santiago de Chile en agosto de 1959, el Estado venezolano representado por el Dr. Ignacio Luis Arcaya, ministro de Relaciones Exteriores, suscribió el acta final con la cual se resuelve "crear una Comisión Interamericana de Derechos Humanos (...) encargada de promover el respeto de tales derechos" ${ }^{4}$.

En el mes de noviembre de 1969, en San José de Costa Rica se celebró la Conferencia Especializada Interamericana, en ella se adoptó la Convención Americana sobre Derechos Humanos (Pacto de San José), firmada por 25 de los

\footnotetext{
2 Caso en el que cuatro ciudadanos chilenos fueron condenados por un tribunal militar a cadena perpetua en Perú, la Corte IDH, al abocar el conocimiento de los hechos concluye que condenar a civiles ante la jurisdicción militar es totalmente contrario y violatorio a la Convención Americana; por lo anterior, la Corte declara la invalidez del proceso realizado contra ellos y condena al Estado peruano a realizarles un juicio justo.

3 Pellegrini (2010), p. 86.

4 Acta Final de la V Reunión de Consulta de Ministros de Relaciones Exteriores, 1959.
} 
Estados miembros de la OEA, entre ellos Venezuela. El primer artículo de esta Convención afirma que los Estados parte "se comprometen a respetar los derechos y libertades reconocidos en ella y a garantizar su libre y pleno ejercicio a toda persona que esté sujeta a su jurisdicción" 5 .

Venezuela revalida su compromiso con los Derechos Humanos, no sólo con la firma del Tratado en 1969, sino con su ratificación años más tarde. A partir de allí, se adhieren al ordenamiento jurídico venezolano todos los derechos consagrados en dicho instrumento y sus dos órganos de funcionamiento: la Comisión Interamericana y la Corte Interamericana.

La ley aprobatoria de la Convención Americana se publicó en Gaceta Oficialel martes 14 de junio de $1977^{6}$, y Venezuela depositó su instrumento de ratificación el 9 de agosto de 1977; sin embargo, este Tratado entró en vigor el 18 de julio de 1978 conforme al artículo 74.2 de la misma, que establece que "tan pronto como once Estados hayan depositado sus respectivos instrumentos de ratificación o de adhesión, la Convención entrará en vigor"7.

$\mathrm{Al}$ ratificar el instrumento, Venezuela formuló una reserva sobre el artículo ocho, ordinal primero ${ }^{8}$ de la Convención, en el sentido que la Constitución venezolana permite que "los reos de delito contra la cosa pública podrán ser juzgados en ausencia con las garantías y en la forma que determine la ley" ${ }^{9}$, aspecto que no menciona la Convención Americana.

En 1981, Venezuela se sometió a la competencia jurisdiccional de la Corte, desde tal fecha, se han emitido 19 sentencias contra el Estado venezolano por no haber garantizado la protección de los derechos a algunos de sus ciudadanos.

Venezuela a lo largo de su historia ha sufrido transformaciones políticas y sociales, que se han visto reflejadas en su norma constitucional, evidencia de ello, son los cambios en su conformación de Estado, pasando a ser Estado democrático y social de Derecho y de Justicia en la actual Constitución de 1999. El preámbulo reza que el motivo de este cambio es "refundar la República", con este fin se lleva

\footnotetext{
5 Convención Americana de Derechos Humanos, 1969, artículo 1.

6 Ley aprobatoria de la Convención Americana de Derechos Humanos, 1977.

7 Convención Americana de Derechos Humanos, 1969, artículo 74.2.

8 "Toda persona tiene derecho a ser oída, con las debidas garantías y dentro de un plazo razonable, por un juez o tribunal competente, independiente e imparcial, establecido con anterioridad por la ley, en la sustanciación de cualquier acusación penal formulada contra ella, o para la determinación de sus derechos y obligaciones de orden civil, laboral, fiscal o de cualquier otro carácter" (CADH, 1969, artículo 8.1).

9 Constitución de la República Bolivariana de Venezuela, 1961, artículo 60, ordinal 5.
} 
a cabo una reorganización del poder público, de la clásica división en tres poderes (Ejecutivo, Legislativo y Judicial) a la pentadivisión actual que incluye el poder ciudadano y el poder electoral, estructura que de acuerdo con Brewer-Carías "es engañosa, pues encubre un peligroso sistema de sujeción de unos poderes a otros, que constituyen la puerta abierta a la concentración del Poder Público y al autoritarismo" 10 .

En la misma línea, la nueva Constitución (fruto de la imperiosa necesidad de reformar el Poder Judicial) crea el Tribunal Supremo de Justicia que reemplazaría a la antigua Corte Suprema de Justicia, estableciendo garantías para su autonomía e imparcialidad; reconociendo en el artículo 265 que para la destitución de magistrados, se requería la mayoría de las dos terceras partes de los miembros de la Asamblea Nacional, posesionándose de esta manera 20 magistrados distribuidos en seis salas ${ }^{11}$.

El TSJ inició labores con el objetivo de depurar la justicia y lograr la materialización de los derechos de forma efectiva, intenciones que se vieron truncadas cuando el Tribunal se convirtió en el centro de múltiples controversias, ya que las divisiones entre opositores y seguidores del presidente Chávez se hacían notables en la jurisprudencia de sus diferentes salas.

Prueba de ello, fue la tensión que trajo consigo la decisión del Consejo Nacional Electoral (CNE) de invalidar 876.01712 firmas recolectadas por la oposición para revocar al presidente Chávez en 2004, ante esta decisión, la Sala Electoral del TSJ (con mayoría opositora) revisó el caso, instando al CNE que desaplicara a las firmas recolectadas el requisito de ratificación ${ }^{13}$ y convocara al referendo revocatorio en caso de encontrar válidas el $20 \%$ de las firmas. Sin embargo, una semana después, el 23 de marzo de 2004, la Sala Constitucional del mismo Tribunal (con mayoría chavista), estudió la decisión mediante la sentencia de expediente No 04-0620, declarando "nula la sentencia No 24 dictada el 15 de marzo de 2004, por la Sala Electoral Accidental del Tribunal Supremo de Justicia"14.

10 Brewer-Carías (2007), p. 58.

11 "El Tribunal Supremo de Justicia funcionará en Sala Plena y en Sala Constitucional, Político Administrativa, Electoral, de Casación Civil, de Casación Penal y de Casación Social, cuyas integraciones y competencias serán determinadas por su ley orgánica”. (Constitución de la República Bolivariana de Venezuela, 1999, artículo 262).

12 Consejo Nacional Electoral, Resolución No 040302-131, de 2 de marzo de 2004.

13 "De la manifestación de voluntad de los titulares de esas firmas" (Sala Electoral del Tribunal Supremo de Justicia, Rol No 24, de 15 de marzo de 2004).

14 Sala Constitucional del Tribunal Supremo de Justicia, Sentencia Rol No 04-0620, de 23 de marzo de 2004. 
Esta polarización provocó que el Ejecutivo promoviera la nueva Ley Orgánica del Tribunal Supremo de Justicia, cuyo principal cambio fue aumentar el número de magistrados de 20 a $32^{15}$, causando una parcialidad innegable al modificar las condiciones de escogencia de los magistrados hasta por mayoría simple, posesionando una mayoría chavista en el Tribunal Supremo de Justicia, pues como afirma el informe de Human Rights Watch, tal reforma trajo como consecuencia "alterar radicalmente el equilibrio de poder dentro del máximo tribunal del país, asegurándose que cada una de sus salas estuviera bajo el control de magistrados que apoyaban la agenda política del gobierno"16. Debilitando el principio de separación de poderes, establecido en el artículo 136 de la Constitución venezolana.

El 10 de septiembre de 2012, previa solicitud de la Sala Constitucional17, Venezuela denunció el Tratado conforme al artículo 78.1 de la Convención ${ }^{18}$, que establece las condiciones y el procedimiento que debe seguir un Estado parte para retirarse oficialmente del Tratado, formalidad cumplida por el gobierno venezolano; a partir de este momento, Venezuela quedó exenta de la jurisdicción de la Corte IDH y el Tribunal Regional, sin competencia para conocer nuevos casos de violaciones de Derechos Humanos que se presenten con posterioridad al 10 de septiembre de 2013. Vale recalcar que la Comisión Interamericana al ser un órgano de la OEA, sigue teniendo competencia sobre el Estado venezolano para velar por la protección de los derechos.

La anterior situación fáctica ha traído como consecuencia que la Sala Constitucional del TSJ haya declarado la inejecutabilidad de diversos fallos proferidos contra el Estado venezolano. Lo que en principio genera un panorama de inseguridad jurídica que debe ser analizado a la luz de la Convención Americana y del ordenamiento jurídico venezolano, con la finalidad de determinar los fundamentos jurídicos que sustentan su decisión.

15 "La Sala Constitucional estará integrada por siete magistrados o magistradas, y las demás Salas por cinco magistrados o magistradas". (Ley Orgánica del Tribunal Supremo de Justicia, 2004, artículo 8).

16 Human Rights Watch (2008), p. 53.

17 Sala Constitucional del Tribunal Supremo de Justicia, Rol No 1939, de 18 de diciembre de 2008.

18 "Los Estados Partes podrán denunciar esta Convención después de la expiración de un plazo de cinco años a partir de la fecha de entrada en vigor de la misma y mediante un preaviso de un año, notificando al Secretario General de la Organización, quien debe informar a las otras partes". (Convención Americana de Derechos Humanos, 1969, artículo 78.1). 


\section{EFECTIVIDAD}

La efectividad de una sentencia consiste en el cumplimiento eficaz de la misma. ¿Pero cómo se logra que una sentencia sea efectiva? Según lo ha considerado la Corte IDH "para lograr plenamente la efectividad de la sentencia la ejecución debe ser completa, perfecta, integral y sin demora"19. Por tanto, la ejecución es un presupuesto de efectividad, convirtiéndose en la etapa más importante de cualquier proceso, ya que una vez emitida la sentencia lo que las partes esperan es que se materialice.

Ayala afirma que "la eficacia jurídico-procesal de las sentencias se desenvuelve en dos direcciones: A) ejecutiva: relativa a la actividad judicial tendiente a la ejecución del fallo, con o sin la voluntad del obligado, adoptándose las medidas que fuesen necesarias; y B) declarativa: relativa a la influencia del fallo en ulteriores actividades declarativas de carácter jurisdiccional, es decir, a la imposibilidad de que otro órgano jurisdiccional dicte una sentencia sobre el asunto" 20 . Por tanto, se hace necesaria la concurrencia de estos dos resultados para garantizar la eficacia de la sentencia.

Es indispensable para la real efectividad de los sistemas internacionales de Derechos Humanos "que existan medios para supervisar y exigir el cumplimiento hasta obtenerlo"21. Estos medios deberían comprender dos acciones propias que son: supervisar y exigir el cumplimiento, la primera entendida como la facultad de hacerle seguimiento al Estado para ver si ha efectuado los puntos resolutivos de la sentencia y, la segunda, como la facultad de sancionar el incumplimiento de los Estados.

Con respecto a las labores de ejecución, el Tratado enfatiza que deben correr por cuenta del Estado condenado, así lo afirma la Corte IDH al establecer que "en un ordenamiento basado sobre el principio del Estado de Derecho todas las autoridades públicas, dentro del marco de su competencia, deben atender las decisiones judiciales, así como dar impulso y ejecución a las mismas sin obstaculizar el sentido y alcance de la decisión ni retrasar indebidamente su ejecución”22. Lo que representa una obligación clara de ejecutar la sentencia de manera íntegra y dentro del plazo determinado.

19 Corte IDH, Caso Mejía Idrovo vs. Ecuador, de 5 de julio de 2011 (fundamento 105).

20 Ayala (2007), p. 136.

21 GarCía (2002), p. 230.

22 Corte IDH, Caso Mejía Idrovo vs. Ecuador, de 5 de julio de 2011 (fundamento 106). 
La efectividad también se relaciona de manera directa con la tutela judicial efectiva, interpretada como un principio para los operadores judiciales y como una garantía para las personas. Ha sido definida como "el derecho que tiene toda persona, como integrante de la sociedad a tener acceso efectivo a los órganos jurisdiccionales para el ejercicio y la defensa de sus derechos, en el marco del debido proceso, justo y legal a fin de obtener una resolución fundada en derecho que ponga fin al proceso; y a la efectividad de esa tutela judicial" 23 .

De allí, que la tutela judicial efectiva busca no sólo garantizar el acceso a un Tribunal, sino que exige que todo ciudadano vea resuelto su problema jurídico y esto sólo se da cuando haya una efectiva ejecución de la sentencia, para ello, la misma Convención consagró en su artículo 25.1 este principio, al afirmar que "toda persona tiene derecho a un recurso sencillo y rápido o a cualquier otro recurso efectivo ante los jueces o tribunales competentes, que la ampare contra actos que violen sus derechos fundamentales reconocidos por la Constitución, la ley o la presente convención, aun cuando tal violación sea cometida por personas que actúen en ejercicio de sus funciones oficiales" 24 .

$\mathrm{LaCADH}$ le ha otorgado a la Corte la facultad de velar por el cumplimiento de los compromisos adquiridos por los Estados, norma que a su vez le permite tomar medidas tendientes al cumplimiento de sus fallos, función que resulta relevante, pues de nada serviría que las decisiones adoptadas por este organismo fueran meramente declarativas y no ejecutables; lo que se buscó fue dotar de jurisdicción a un organismo que pudiera resolver esa carencia de justicia que en ocasiones encuentran las personas en su propio país.

El Tratado, además de contener un catálogo de Derechos Humanos, es un instrumento jurídico que busca proteger a los titulares de éstos, partiendo de la base que el acceso a la justicia es una garantía fundamental de toda persona. La $\mathrm{CADH}$ no restringe el derecho de acción colocando características especiales en la parte demandante, al contrario, establece que "cualquier persona o grupo de personas, o entidad no gubernamental legalmente reconocida en uno o más Estados miembros de la Organización, puede presentar a la Comisión peticiones que contengan denuncias o quejas de violación de esta Convención por un Estado parte"25.

23 Ramírez (2013), p. 3.

24 Convención Americana de Derechos Humanos, 1969, artículo 25.1.

25 Convención Americana de Derechos Humanos, 1969, artículo 44. 
En conclusión, la CADH aspira infructuosamente que los Estados firmantes materialicen este derecho ejecutando todas las sentencias proferidas en su contra. Sin embargo, el Estado venezolano no ha ejecutado algunas sentencias provenientes de la Corte, por lo que se procederá a determinar los argumentos expuestos.

\section{Argumentos de la Sala Constitucional}

A partir de la Constitución de 1999 se crea en Venezuela la Sala Constitucional, centralizando en ella el control de la Constitución, lo que ha llevado a que gran parte de la doctrina discuta sobre sus funciones y naturaleza, considerando incluso que ha asumido funciones de Tribunal Supremo de Justicia en pleno; es por ello, que para Hernández existen tres factores que han incidido en la práctica de la justicia constitucional, que son: "(i) el inadecuado marco constitucional de la Sala Constitucional; (ii) el deficiente sistema de designación de los magistrados de la Sala Constitucional, en un contexto más amplio de deterioro de la autonomía del poder judicial, y (iii) la ampliación y desfiguración de las funciones de la Sala Constitucional en su propia jurisprudencia" 26 .

$\mathrm{Al}$ ser el Tribunal Supremo de Justicia el órgano garantizador de los preceptos constitucionales y máximo intérprete de la norma suprema, su competencia se considera "como de derecho estricto que tiene que estar establecida expresamente en la Constitución, y no puede ser deducida por vía de interpretación"27, establecimiento constitucional que se observa en su artículo 336, cuando atribuye a la Sala Constitucional "1. Declarar la nulidad total o parcial de las leyes nacionales y demás actos con rango de ley de los cuerpos legislativos nacionales que colidan con esta Constitución. 2. Declarar la nulidad total o parcial de las Constituciones y leyes estatales, de las ordenanzas municipales y demás actos de los cuerpos deliberantes de los Estados y Municipios dictados en ejecución directa e inmediata de la Constitución y que colidan con ésta. 3. Declarar la nulidad total o parcial de los actos con rango de ley dictados por el Ejecutivo Nacional que colidan con esta Constitución (...)"28.

26 Hernández (2016), p. 81.

27 BREWER-CARÍAS (2012), p. 356.

28 Constitución de la República Bolivariana de Venezuela, 1999, artículo 336. 
Sin embargo, a través de los años bajo su desarrollo jurisprudencial y en contravía de sus funciones constitucionales se ha atribuido facultades ${ }^{29}$ que no le corresponden, al crear mecanismos como el recurso extraordinario o excepcional de revisión de sentencias, que podrían conllevar a "obstruir la sana operatividad del engranaje de los otros órganos integrados al poder público"30.

La función de vigilancia de la Constitución en relación directa con los Tratados, las medidas cautelares y las sentencias emanadas del organismo internacional tienen su origen y fundamento en la sentencia 1077 de 2000 (caso Servio Tulio León Briceño), considerando la Sala Constitucional que es quien deberá aclarar y reconocer su vigencia en el derecho interno, por cuanto a ésta "corresponde con carácter exclusivo la interpretación máxima y última de la Constitución, y debido a tal exclusividad, lo natural es que sea ella quien conozca de los recursos de interpretación de la Constitución" 31 , tal competencia que se asigna resulta lesiva, ya que el recurso es "de carácter abstracto y autónomo, que demuestra como la interpretación, puede traducirse en un importante poder político. De allí que en este caso, a pesar de no estar tal acción consagrada en ninguna parte del texto de la Constitución, esta facultad interpretativa ha permitido una ampliación de atribuciones que la propia Sala Constitucional asegura a su favor" 32 .

Posteriormente, en la sentencia 1309 de $2001^{33}$ se concluyó que toda interpretación de la Carta Magna debería ser compatible con el proyecto político de la Constitución, con el fin de que no se vea alterada la realización del mismo, posición que se reitera en la sentencia 23 de $2003^{34}$, donde dispone que la interpretación debe hacerse conforme a la Constitución.

29 “a) La creación del recurso autónomo de interpretación de la Constitución, b) el establecimiento del recurso extraordinario o excepcional de revisión de sentencias, c) la ampliación de los poderes de avocamiento de todas las Salas que componen el Tribunal Supremo de Justicia, d) la extensión de las atribuciones para la actuación de oficio de la Sala Constitucional, e) la ampliación de atribuciones respecto al control de la constitucionalidad por omisión de los cuerpos legislativos, f) la asunción del Monopolio de la interpretación de la Constitución, mediante la restricción de los poderes del control difuso de la Constitucionalidad y g) el monopolio de la interpretación en materia de Tratados de Derechos Humanos en el orden interno". BOSCÁN (2007), p. 32.

30 Carrillo (2005), p. 6.

31 Sala Constitucional del Tribunal Supremo de Justicia, Rol No 1077, de 22 de septiembre de 2000.

32 BOSCÁN (2007), p. 36.

33 Sala Constitucional del Tribunal Supremo de Justicia, Rol No 1309, de 19 de julio de 2001.

34 Sala Constitucional del Tribunal Supremo de Justicia, Rol No 23, de 22 de enero de 2003. 
Las anteriores referencias, junto con la sentencia 1013 de 2001 en la que se reconoce la supremacía del TSJ frente a las instancias internacionales, resultan ser el claro antecedente de la sentencia 1942 de 2003, donde por primera vez se desconocen las sentencias de la Corte IDH.

De conformidad con el artículo 23 de la Constitución venezolana, los Tratados, pactos y convenciones relativos a Derechos Humanos, tienen jerarquía constitucional y prevalecen en el orden interno, siendo su aplicación inmediata siempre que establezcan condiciones más favorables; no obstante, ésta no es directa, pues en la sentencia 1942 de julio de 2003 se dice que al incorporarse al ordenamiento jurídico venezolano instrumentos internacionales sobre Derechos Humanos "el máximo y último intérprete de ellas, a los efectos del derecho interno es esta Sala Constitucional, que determina el contenido y alcance de las normas y principios constitucionales" $35 \mathrm{y}$, por tanto, "ante antinomias o situaciones ambiguas entre los derechos contenidos en los instrumentos internacionales señalados y la Constitución, corresponderá a la Sala Constitucional interpretar cuál es la disposición más favorable"36. La atribución de interpretación es constantemente asumida en los fallos, como ocurre en la sentencia 1175 de 2015, donde se dice que ésta "tiene la facultad, incluso de oficio" 37 , de confrontar frente a los fallos las normas internas constitucionales y los Tratados que integran el sistema constitucional venezolano.

Desde el punto de vista legislativo, en consonancia con las decisiones antes tomadas, en el año 2004 se promulga la Ley Orgánica del Tribunal Supremo de Justicia, publicada en Gaceta Oficial No 37.942, reconociendo dentro de las funciones del Tribunal (artículo 5 numeral 52) el control concentrado de constitucionalidad en cabeza de la Sala Constitucional.

Otro antecedente del evidente incumplimiento de las sentencias de la Corte IDH, es la sentencia 1461 de 200638 (el Caracazo) donde la Sala Constitucional del TSJ da lugar a la acción de amparo interpuesta por un funcionario policial relacionado con los hechos, dejando sin efecto la apelación que hubiese permitido dar seguimiento a la investigación, desconociendo así lo ordenado por la Corte IDH.

En el año 2008 resulta trascendental la sentencia 1939, porque afirma que la Convención es coadyuvante o complementaria y no puede desconocer "la

35 Sala Constitucional del Tribunal Supremo de Justicia, Rol No 1942, de 15 de julio de 2003.

36 Ídem.

37 Sala Constitucional del Tribunal Supremo de Justicia, Rol No 1175, de 22 de junio de 2015.

38 Sala Constitucional del Tribunal Supremo de Justicia, Rol No 1461, de 27 de julio de 2006. 
norma suprema y el fundamento del ordenamiento jurídico"39, además reza que "el citado artículo 23 de la Constitución no otorga a los tratados internacionales sobre Derechos Humanos rango 'supraconstitucional', por lo que, en caso de antinomia o contradicción entre una disposición de la Carta Fundamental y una norma de un pacto internacional, correspondería al Poder Judicial determinar cuál sería la aplicable" 40 . Lo que genera una postura "inserta dentro de los dogmas de un monismo con supremacía del derecho interno sobre el derecho internacional propio de inicios del siglo XX" 41 ; asimismo, la sentencia es importante por la atribución que se toma el Poder Judicial, solicitando "al Ejecutivo Nacional procedan a denunciar esta convención, ante la evidente usurpación de funciones en que ha incurrido la Corte Interamericana de los Derechos Humanos (...)"42.

En ese mismo año se expide la sentencia 1265 de 2008 que reafirma el criterio de supremacía constitucional, señalando que sólo se puede emplear de manera preferente los Tratados, pactos o convenios sobre Derecho Humanos que "contengan norma más favorable a las de la Constitución” ${ }^{43}$; además, en la sentencia 1175 de 2015, añade que prevalecen si, y sólo si, resultan más favorables "lo que al entender de este órgano constitucional no comprende la ejecución de fallos o recomendaciones dictadas por los órganos convencionales" 44 .

En lo que respecta a la protección de los Derechos Humanos, específicamente el derecho a la información, se encuentra la sentencia 745 de 2010 que crea una "decisión negadora o reduccionista del DIDH, toda vez que de acuerdo con la Corte IDH, toda persona, sin necesidad de acreditar un interés especial, tiene el derecho humano de acceso a la información que el Estado administre o produzca o que deba administrar o producir. En este sentido, el Estado tiene la obligación internacional de suministrar al público información de forma oficiosa y continua, y establecer mecanismos ágiles y eficientes de acceso a la información que sea solicitada" 45 .

39 Constitución de la República Bolivariana de Venezuela, 1999, artículo 7.

40 Sala Constitucional del Tribunal Supremo de Justicia, Rol No 1939, de 18 de diciembre de 2008.

41 Márquez (2014), p. 42.

42 Sala Constitucional del Tribunal Supremo de Justicia, Rol No 1939, de 18 de diciembre de 2008.

43 Sala Constitucional del Tribunal Supremo de Justicia, Rol No 1265, de 5 de agosto de 2008.

44 Sala Constitucional del Tribunal Supremo de Justicia, Rol No 1175, de 22 de junio de 2015.

45 MeIER (2011), pp. 329-376. 
Por último, expresamente se declaran inejecutables los fallos de la Corte IDH en las sentencias 1547 de 2011 y 1175 de 2015, la primera en el caso de Leopoldo López y la segunda Radio Caracas Televisión (RCTV), asumiendo la sala las competencias que se otorga en la 1077 y desconociendo lo fallado por la Corte.

Con la finalidad de señalar los argumentos que sustentan la inejecución de las sentencias, se hace necesario dejar clara la posición que reconoce la prelación de la norma constitucional, de sus fundamentos filosóficos y la no violación a la soberanía nacional. En virtud de lo anterior, podemos clasificar los argumentos del Tribunal en dos sentidos:

\section{A. Violación del ordenamiento jurídico venezolano}

El argumento para no cumplir los fallos se fundamenta en la interpretación que hizo la Sala Constitucional en sentencia 1942 de 2003, respecto a la naturaleza del Tratado reconociendo que éstos: "nacen porque varias naciones, en determinadas áreas, escogen un tribunal u organismo común que dirime los litigios entre ellos, o entre los países u organismos signatarios y los particulares nacionales de esos países signatarios (...) pero al ellos ejecutarse dentro del territorio nacional conforme a las normas de ejecución en vigor en el país condenado, la ejecución no puede colidir con las normas constitucionales" 46 .

Asimismo, menciona que la no ejecución por las razones anteriores no genera responsabilidad internacional, ya que los fallos de la Corte IDH no se pueden ejecutar forzosamente, debido a que en el Tratado suscrito Venezuela no cedió la soberanía nacional, lo que si sucede, por ejemplo, con el Estatuto de Roma, el cual puede clasificarse como un tribunal supranacional cuyas decisiones "pueden resultar obligatorias respecto a lo decidido, creando responsabilidad internacional por el incumplimiento" 47 .

La decisión reza: "la ejecución en el territorio del Estado Contratante, se hace conforme a las normas de dicho Estado, por lo que, a juicio de esta Sala, un fallo violatorio de la Constitución de la República Bolivariana de Venezuela se haría inejecutable en el país”48. Bajo el mismo argumento en la sentencia 1175 de 2015 se hace referencia a la carta que oficializa la salida de la jurisdicción de la Corte IDH, en la

46 Sala Constitucional del Tribunal Supremo de Justicia, Rol No 1942, de 15 de julio de 2003.

47 Ídem.

48 Ídem. 
que se expresa textualmente: "La Corte Interamericana no puede pretender excluir, desconocer, ni sustituir el ordenamiento constitucional de los Estados Parte, pues la protección internacional que de ella se deriva es coadyuvante o complementaria de la que ofrece el derecho interno de los Estados americano" 49 .

Por otro lado, en la sentencia 1309 de 2001 se reconoce que ante un conflicto entre las normas y los principios, se debe privilegiar el proyecto político de la Constitución, pues "no deben afectar la vigencia de dicho proyecto con elecciones interpretativas ideológicas que privilegien los derechos individuales a ultranza o que acojan la primacía del orden jurídico internacional sobre el derecho nacional en detrimento de la soberanía del Estado"50.

Por lo anterior, se acude a lo que denominan como principio de favorabilidad, según el cual la aplicación de las normas del Tratado y las sentencias deberán tener "una doble justificación, a saber, la interna o coherencia con el sistema jurídico, y la externa o adecuación con la mejor teoría política que subyazca tras el sistema y con la moralidad institucional que le sirve de base axiológica" 51.

Entonces, la interpretación que se quiere aplicar no debe sólo someterse a la Constitución venezolana desde el punto de vista formal, sino estar acorde con el espíritu de ella, es decir, con la mejor teoría política del Estado venezolano. De conformidad con lo anterior, el argumento utilizado para inejecutar las sentencias se fundamenta en la prevalencia de la norma nacional y el respeto a la misma, pues "El respeto al derecho interno se convierte así en un requisito previo, que sirve de dique de contención a que se dicten fallos que desconozcan, al menos, las normas constitucionales de los suscritores de los Convenios o Tratados" 52 . Posición que se mantiene en el caso Leopoldo López, en el que se habla de un "estándar mínimo de adecuación del fallo al orden constitucional interno"53.

Por las mismas razones expuestas se negó la reincorporación de los jueces en el caso Apitz Barbera y otros por "desconocer la firmeza de decisiones administrativas y judiciales que han adquirido la fuerza de la cosa juzgada, al ordenar la reincorporación de los jueces destituidos" 54 .

49 Sala Constitucional del Tribunal Supremo de Justicia, Rol No 1175, de 22 de junio de 2015.

50 Sala Constitucional del Tribunal Supremo de Justicia, Rol No 1309, de 19 de julio de 2001.

51 Ídem.

52 Sala Constitucional del Tribunal Supremo de Justicia, Rol No 1942, de 15 de julio de 2003.

53 Sala Constitucional del Tribunal Supremo de Justicia, Rol No 1547, de 17 de octubre de 2011.

54 Sala Constitucional del Tribunal Supremo de Justicia, Rol No 1939, de 18 de diciembre de 2008. 


\section{B. Violación de la soberanía nacional}

Además de invocar la violación del ordenamiento jurídico venezolano para no cumplir con algunas sentencias, también arguye la Sala Constitucional del TSJ la violación de la Soberanía Nacional.

El concepto de soberanía nació bajo la idea de regirse dentro de un orden jurídico interno, donde la relación que se daba era sólo entre el Estado y sus ciudadanos, justificando una posición irreconciliable en el concepto, entendiéndose como un "(...) poder absoluto, superior e incontrolado que tiene la decisión final con respecto a la adopción y promulgación de las normas jurídicas que deben regir esa sociedad" 55 .

En la actualidad, la soberanía ha evolucionado para dar paso a las relaciones entre Estados, relativizándolo y dando cabida al cumplimiento de los compromisos internacionales, de allí que en las diferentes Constituciones los Tratados tengan un papel preponderante.

La jurisprudencia venezolana difiere de la noción contemporánea, pues afirma que la soberanía "no es susceptible de relativización, implica, entre otros, los atributos de legislar y administrar justicia, por lo que, un Estado soberano excluye, por definición y antonomasia, la intervención de otro poder político en esos y otros asuntos" 56 , por eso, frente a las sentencias "de la justicia supranacional o transnacional para ser ejecutadas dentro del Estado, tendrán que adaptarse a su Constitución. Pretender en el país lo contrario sería que Venezuela renunciara a la soberanía" 57.

En consonancia con lo anterior, el Estado venezolano ha estimado deteriorada su soberanía, como lo anuncia la Sala Constitucional frente al fallo emitido por parte de la Corte Interamericana donde se ordena la reincorporación de los exjueces de la Corte Primera de lo Contencioso Administrativo, quienes habían sido destituidos por haber incurrido en un presunto "error judicial inexcusable"; frente al caso, la sentencia 1939 de 2008 argumenta que el organismo regional dictó pautas sobre su gobierno y administración que no le correspondían decretar, violentando la soberanía de este Estado, resultando de inadmisible ejecución todo lo dictado en su contra. Además, en la sentencia 1547 de 2011 se aduce que la Corte IDH ha desviado la teleología de la Convención "usurpando funciones

55 Naranjo (2003), p. 223.

56 Sala Constitucional del Tribunal Supremo de Justicia, Rol No 100, de 20 de febrero de 2015.

57 Sala Constitucional del Tribunal Supremo de Justicia, Rol No 1942, de 15 de julio de 2003. 
cual si fuera una potencia colonial y pretendiendo imponer a un país soberano e independiente criterios políticos e ideológicos absolutamente incompatibles" 58 .

Esta posición aunque mayoritaria no ha sido la de todos los magistrados, pues en lo referente a los Tratados sobre Derechos Humanos, cabe resaltar el salvamento de voto realizado por el magistrado Pedro Rafael Rondón Haaz, en la sentencia 1265 de 2008, quien afirma que "del dogma de la Soberanía corre a cuenta, principalmente, del Derecho Internacional de los Derechos Humanos, pues en nuestro tiempo, afortunadamente, ningún Estado puede creerse con título omnímodo que lo habilite para tratar como quiera a sus 'ciudadanos', pues siempre habrá de hacerlo con respeto y acatamiento a los estándares mínimos del Derecho Internacional"59, es así que según el magistrado cuando se esté frente a casos que traten temas sobre Derechos Humanos, no está a cargo del Estado decidir, si cumple o no lo fallado contra éste, pues aunque el Estado se refugie bajo el derecho de su soberanía, prevalecen los derechos de los ciudadanos.

De acuerdo con lo anterior, es válido preguntarse si la soberanía de un Estado da la potestad a éste para revisar y decidir si ejecuta o no los fallos proferidos por los tribunales transnacionales. El doctrinante Carrillo manifiesta que "La soberanía del Estado (...) simboliza la relevancia de la voluntad y el consentimiento del Estado en el proceso de creación, desarrollo progresivo y aplicación del Derecho internacional"60. Bajo este entendido, se puede determinar que el argumento esgrimido no tendría cabida, pues la soberanía que se alega violada por el tribunal transnacional es la misma que le permite aceptar el Tratado y otorgar competencia de buena fe a dichos Tribunales; y en caso de incompatibilidad por cambio del sistema político, lo jurídicamente correcto es adecuar el sistema interno o la Constitución a los requerimientos del Tratado o bien apartarse del mismo, pero con la obligación de cumplir los fallos proferidos con anterioridad, so pena de la incursión en responsabilidad internacional por el incumplimiento de las obligaciones contraídas.

A la luz de la Convención de Viena, conocido como el "tratado de tratados", los argumentos sostenidos resultan improcedentes, pues su artículo 27 consagra que "una parte no podrá invocar las disposiciones de su derecho interno como justificación del incumplimiento de un tratado" 61 , por lo tanto, en caso de haber

58 Sala Constitucional del Tribunal Supremo de Justicia, Rol No 1547, de 17 de octubre de 2011.

59 Sala Constitucional del Tribunal Supremo de Justicia, Rol No 1265, de 5 de agosto de 2008.

60 Carrillo (1969), p. 85.

61 Convención de Viena sobre el Derecho de los Tratados, 1969, artículo 27. 
antinomia entre una disposición internacional sobre Derechos Humanos (como es la Convención Americana) y la Constitución, esta última debe ajustarse de acuerdo al Tratado y no al contrario, como bien lo expresa en el salvamento de voto el Dr. Pedro Rafael Rondón Haaz, al afirmar que "cuando exista alguna contradicción entre la Constitución y la Convención, el Estado de que se trate debe procurar la reforma del Texto Constitucional para que cumpla con la obligación que asumió en razón del artículo 2 de la última y ésa ha sido la experiencia de los países democráticos en nuestra región" 62 .

\section{LA OBLIGATORIEDAD DE LOS COMPROMISOS ADQUIRIDOS en la Convención Americana de Derechos Humanos}

El artículo 33 de la Convención define a la Corte Interamericana como uno de los órganos "competentes para conocer de los asuntos relacionados con el cumplimiento de los compromisos contraídos por los Estados (...)"63, esto le permite a la Corte no sólo conocer de los casos contenciosos que se sometan a la jurisdicción del sistema, sino también ser el máximo intérprete de la Convención. Así lo afirma el artículo 62.3 del Pacto de San José, disponiendo: "La Corte tiene competencia para conocer de cualquier caso relativo a la interpretación y aplicación de las disposiciones de esta Convención que le sea sometido, siempre que los Estados partes en el caso hayan reconocido o reconozcan dicha competencia, ora por declaración especial, como se indica en los incisos anteriores, ora por convención especial" 64 .

Venezuela después de ratificar el Tratado, reconoció la competencia de la Comisión Interamericana de Derechos Humanos el 9 de agosto de 1977 y el 24 de junio de 1981 se sometió a la jurisdicción de la Corte, quedando de esta forma obligada, pues sólo se tiene función jurisdiccional frente aquellos países que reconocieron su competencia previamente.

Una vez cumplido este requisito, el Estado parte está obligado a acoger las decisiones que allí se tomen sin ningún tipo de excepciones, lo que se conoce también como obligatoriedad de pleno derecho, de no hacerlo así, incurriría en responsabilidad frente al Tratado, la cual se determinará de acuerdo con las

62 Sala Constitucional del Tribunal Supremo de Justicia, Rol No 1265, de 5 de agosto de 2008 (Salvamento de voto del Magistrado Pedro Rafael Rondón Haaz).

63 Convención Americana de Derechos Humanos, 1969, artículo 33.

64 Convención Americana de Derechos Humanos, 1969, artículo 62.3. 
condiciones en que el mismo ha sido ratificado. En el caso de Venezuela se hizo una reserva referente a la investigación penal que le permite juzgar a los reos en ausencia ${ }^{65}$; no obstante, nada dice sobre la ejecución de las sentencias de la Corte IDH, por lo que se ha de entender que su compromiso fue ejecutarlas de pleno derecho.

Los fallos emitidos por la Corte IDH se caracterizan por ser vinculantes, pues “(...) los elementos normativos y las decisiones jurisdiccionales que emanen de este sistema no son aislados e independientes del sistema legal interno, de hecho, la efectividad en cuanto a la protección de los derechos fundamentales, solamente está garantizada en tanto y cuanto el orden interno asuma en lo referente a su contenido los alcances y efectos de estas normas y decisiones emergentes del Sistema Interamericano de Protección de Derechos Humanos"66. Lo anterior no significa que los Estados miembros puedan utilizar su sistema interno como excusa para dejar de ejecutar los fallos; por el contrario, ambos sistemas deben contribuir activamente en la protección efectiva de los derechos, en esto consiste la sistematicidad (parte de la normatividad está inmersa en la legislación interna de cada país, mientras que la otra se encuentra en el articulado del Tratado), creando una especie de bloque normativo que junto a la jurisprudencia de la Corte regula el sistema.

En el sistema interamericano las sentencias proferidas poseen carácter inmutable, por lo que "el fallo de la Corte será definitivo e inapelable. En caso de desacuerdo sobre el sentido o alcance del fallo, la Corte lo interpretará a solicitud de cualquiera de las partes (...)"67. De igual forma, el artículo 68.1 expresa: "los Estados Partes en la Convención se comprometen a cumplir la decisión de la Corte en todo caso en que sean partes"68. Esto no sólo reafirma la obligatoriedad de sus sentencias, sino también la facultad que tiene este Tribunal de interpretar su propia jurisprudencia en caso de ambigüedades, sin otorgar a los Estados esta facultad.

Para la Convención Americana, el consentimiento del Estado implica la voluntad de obligarse y le otorga a la sentencia proferida por la Corte IDH carácter de absoluta, surtiendo efectos de forma automática sin requerir ningún acto legislativo

65 “...Los reos de delito contra la cosa pública podrán ser juzgados en ausencia con las garantías y en la forma que determine la ley" (Constitución de la República Bolivariana de Venezuela, 1961, artículo 60 ordinal 5).

66 Cuéllar y SaAvedra (2010), p. 27.

67 Convención Americana de Derechos Humanos, 1969, artículo 67.

68 Convención Americana de Derechos Humanos, 1969, artículo 68.1. 
interno, pues como lo afirma Faúndez, "El lenguaje de la Convención refleja la intención de las partes en el sentido que sus disposiciones tengan efecto en el Derecho interno inmediatamente después de su ratificación"69. Además, el artículo 26 de la Convención de Viena establece el principio de "pacta sunt servanda", señalando que "todo tratado en vigor obliga a las partes y debe ser cumplido por ellas de buena fe"70, convirtiendo a la buena fe en la piedra angular del sistema interamericano, confiando en que los Estados serán totalmente competentes a la hora de ejecutar y cumplir las sentencias proferidas en su contra, etapa que busca materializar el principio de tutela judicial efectiva.

Es por eso que el sistema fue diseñado bajo el principio de garantía colectiva ${ }^{71}$, comprometiéndose todos los Estados a vigilar el cumplimiento de las obligaciones contraídas en el Tratado, para ello el artículo 69 establece que el fallo debe ser notificado no solamente a las partes del proceso, sino también transmitido a todos los Estados parte de la Convención ${ }^{72}$; la vigilancia de los compromisos se hace desde dos enfoques: primero, en relación con el cumplimiento de cada fallo $y$, segundo, al cumplimiento del Tratado en general.

La primera forma de supervisión que busca asegurar la ejecución del fallo de forma efectiva, consiste en emitir una resolución de cumplimiento, que le solicite al Estado condenado a rendir un informe en el que se especifique cómo ha ejecutado la sentencia proferida en su contra, esta es una etapa trascendental para la eficacia del sistema, así lo afirma el juez Cançado, para quien "la supervisión de sentencias requiere cuidadoso estudio y detenida consideración porque constituye la etapa en la que la labor de la Corte alcanza materialmente a aquellas personas para las cuales se ha concebido el sistema de protección de los Derechos Humanos y en la cual se concretan, de manera más evidente, los beneficios de sus actividades" 73 .

El informe que presenta el Estado, de conformidad con el artículo 69.1, estará acompañado por las observaciones de las víctimas y sus representantes, al que la Comisión "deberá presentar observaciones" 74 y de ser necesario la Corte

\footnotetext{
69 FAÚNDEZ (2004), p. 59.

70 Convención de Viena sobre el Derecho de los Tratados, 1969, artículo 26.

71 Cantón (2013), pp. 255-285.

72 "El fallo de la Corte será notificado a las partes en el caso y transmitido a los Estados partes en la Convención" (CADH, 1969, artículo 69).

73 CANÇADO (2000), p. 111.

74 Reglamento de la Corte IDH, 2001, artículo 69.1.
} 
podrá "convocar al Estado y a los representantes de víctimas a una audiencia para supervisar el cumplimiento de sus decisiones" 75 . El procedimiento no es otra cosa que un llamado de atención a los Estados, para que adopten todas las medidas necesarias para el cumplimiento efectivo del fallo en su contra.

La segunda forma de supervisión, es decir, del cumplimiento del Tratado en general, opera mediante un procedimiento que se realiza anualmente y consiste en someter a consideración de la Asamblea General de la OEA un informe sobre el funcionamiento de la Corte en todo el año inmediatamente anterior, donde se denuncia el incumplimiento de los Estados que se hayan negado a ejecutar los fallos de la Corte $^{76}$. Esta supervisión, tal como estaba planteada, otorgaba al Sistema cierto grado de coercibilidad, al imponer una sanción de carácter moral a los Estados que incumplieran el Tratado; sin embargo, a partir de las reformas hechas en los años 90, en medio del llamado proceso de fortalecimiento del sistema, la Asamblea General de la OEA perdió tal facultad que se confió a la Comisión de Asuntos Jurídicos y Políticos del Consejo Permanente de la OEA77, quien no discute el informe, sino que emite una resolución consensuada que se comunica a la Asamblea General, simplemente aprobándolo ${ }^{78}$.

Habiendo cambiado el destinatario del informe anual presentado por la Corte, la efectividad del sistema puede verse afectada, si se tiene en cuenta que una etapa tan importante como la supervisión de las sentencias, no está siendo tema de debate en la Asamblea General de la OEA, y que el contenido del informe anual lejos de ser una sanción para el Estado incumplido, se ha convertido en un acto

75 Reglamento de la Corte IDH, 2001, artículo 69.3.

76 "La Corte someterá a la consideración de la Asamblea General de la Organización en cada período ordinario de sesiones un informe sobre su labor en el año anterior. De manera especial y con las recomendaciones pertinentes, señalará los casos en que un Estado no haya dado cumplimiento a sus fallos". (Convención Americana de Derechos Humanos, 1969, artículo 65).

77 "La comisión de Asuntos Jurídicos y Políticos considerará los informes del Comité Jurídico Interamericano, la comisión Interamericana de Derechos Humanos, y la Corte Interamericana de Derechos Humanos a los que se refiere el artículo 91 (f) de la Carta. Asimismo, elevará al Consejo Permanente sus informes con observaciones y recomendaciones y los correspondientes proyectos de resolución". (Reglamento del Consejo Permanente de la OEA, 1980, artículo 18).

78 La discusión del informe anual presentado por la Corte IDH ha dejado de ser un procedimiento indispensable para convertirse en potestativo para el Estado incumplido, conforme a esto expresa CÁRDENAS (2015): "En la práctica basta con que el Estado señalado de incumplir una sentencia de la Corte IDH se oponga a que se le exhorte a informar sobre el incumplimiento de una sentencia, para que no se haga tal exhorto en la resolución que aprueba la Comisión de Asuntos Jurídicos y Políticos; y, consecuentemente, en la que aprueba el Consejo Permanente y la Asamblea General". 
más. Por todo esto manifiesta Ayala, "se ha desdibujado y debilitado el rol que podría jugar la Asamblea General como mecanismo de protección colectiva de los Derechos Humanos en el sistema interamericano. Simplemente: los Estados no quieren controlar ni ser controlados por otros Estados"79.

Cabe recordar que el Sistema Regional de Protección de Derechos Humanos instaurado en América tiene como antecedente el modelo europeo, y aunque se implementaron muchas de sus estructuras, se crea una forma de protección diferente, al no existir un órgano coercitivo encargado de supervisar integralmente la efectividad de las sentencias y, por ende, el funcionamiento del sistema; referido a ello, afirma Faúndez que al momento de crearlo "en lo que concierne a los órganos de protección no se contempló la intervención de un órgano político, que desempeñara una función semejante a la que inicialmente desempeñaba el Comité de Ministros del Consejo de Europa. Esta circunstancia ha privado al sistema instaurado por la Convención Americana de la debida eficacia (...)"80, tal falencia radica en que el Sistema Europeo desde su conformación fue claro al encargar de la supervisión de las sentencias al Comité de Ministros ${ }^{81}$, dándole la potestad de tomar medidas en caso de que un Estado se niegue a ejecutar una sentencia ${ }^{82}$, lo que no sucedió en la Convención Americana donde la supervisión de sentencias no estaba contemplada de forma explícita, por lo que la Corte IDH ha asumido dicha función basada en el artículo 65 que le da la potestad de comunicar el incumplimiento de los fallos en su informe anual ${ }^{83}$.

En este punto es importante tener en cuenta que en la normatividad del sistema, las reglas específicas sobre responsabilidad por incumplimiento del Tratado no son claras, inicialmente porque "no detallan las acciones u omisiones que eventualmente deban reputarse como contrarias al deber de los Estados partes de

\footnotetext{
79 Ayala (2007), p. 131.

80 FAúndez (2004), p. 55.

81 "La sentencia definitiva del Tribunal se transmitirá al Comité de Ministros, que velará por su ejecución”. (Convenio Europeo de Derechos Humanos, 1950, artículo 46.2).
}

82 "Si el Tribunal concluye que se ha producido una violación del párrafo 1, remitirá el asunto al Comité de Ministros para que examine las medidas que sea preciso adoptar". (Convenio Europeo de Derechos Humanos, 1950, artículo 46.5).

83 "La Corte someterá a la consideración de la Asamblea General de la Organización en cada período ordinario de sesiones un informe sobre su labor en el año anterior. De manera especial y con las recomendaciones pertinentes, señalará los casos en que un Estado no haya dado cumplimiento a sus fallos". (Convención Americana de Derechos Humanos, 1969, artículo 65). 
respetar y garantizar en sus jurisdicciones los derechos de la persona humana..." 84 , es decir, no cuenta con reglas técnicas que nos permitan saber cuándo un Estado está efectivamente violando el Tratado, dejando a criterio de la Corte Interamericana a motu proprio establecer la posible responsabilidad de cada Estado.

En tal sentido, el juez de la Corte Interamericana Aguiar, hablando de la Carta de la OEA y la Convención Americana, afirma que éstas "no precisan por lo demás, los supuestos en que sería admisible la atribución o la exclusión, o eventualmente la exoneración de la responsabilidad estatal" ${ }^{85}$. Así, en caso de incumplir las obligaciones del Tratado, el Estado en principio no tiene justificación que ampare su incumplimiento, pero tampoco norma imperativa que lo obligue y de donde nazca la supuesta responsabilidad, porque la Convención no establece un procedimiento especial para la ejecución de las sentencias proferidas por la Corte IDH; a lo que sí se refiere de forma clara, es el procedimiento ejecutivo que busca hacer efectiva la parte del fallo que consagra la indemnización, pues afirma que “(...) se podrá ejecutar en el respectivo país por el procedimiento interno vigente para la ejecución de sentencias contra el Estado" 86 . De allí que la ejecución de las sentencias está en cabeza del Estado condenado, quien debe establecer el procedimiento correspondiente, dejando los demás aspectos a la buena fe del Estado.

En lo referente a los términos de ejecución, cada sentencia proferida por la Corte IDH dispone de un determinado tiempo que busca garantizar que el Estado condenado lleve a cabo los puntos resolutivos de la sentencia, esto quiere decir que si bien es autónomo para ejecutar las sentencias de la Corte, el cumplimiento debe hacerse dentro del plazo estipulado, así lo ha dicho la jurisprudencia de la Corte IDH al afirmar que el cumplimiento de la sentencia debe hacerse "de manera pronta, íntegra y efectiva, dentro de los plazos señalados en el propio fallo" 87 , ya que no tendría sentido dejar a la deriva la fecha máxima que la víctima debe esperar para ver materializado su derecho a la justicia. Sin embargo, la $\mathrm{CADH}$ no específica la forma como deben ser ejecutadas las sentencias de fondo, sólo se pronuncia respecto a la indemnización, pudiendo ser ejecutada según el procedimiento interno.

\footnotetext{
84 Aguiar (1993), p. 6.

85 Ídem.

86 Convención Americana de Derechos Humanos, 1969, artículo 68.2.

87 Corte IDH, Caso Gelman vs. Uruguay, de 20 de marzo de 2013, resolución de cumplimiento (fundamento 25).
} 
La carencia de reglas sobre la ejecución de la sentencia es suplida por la legislación interna, a la cual atañe regular la forma en que se deben ejecutar las sentencias amparadas en la propia Convención, autorizando que la ejecución se haga "por el procedimiento interno vigente para la ejecución de sentencias contra el Estado"88, por lo tanto, si el Estado internamente no establece las formas de ejecutar las sentencias de la Corte IDH, este vacío normativo podría estar quebrantando el artículo 2 del Tratado, que expresa la obligación de adoptar las medidas legislativas o de otro carácter, necesarias para hacer efectivo el ejercicio de los derechos y libertades reconocidos en la Convención, pues la no regulación en materia de ejecución de sentencias limita claramente el acceso a la justicia por parte de las víctimas.

El procedimiento antes señalado podría generar dificultad para las víctimas a la hora de buscar la ejecución de una sentencia, ya que se les podría violar principios del Derecho Internacional como la igualdad de las partes y la tutela judicial efectiva, debido a la imposibilidad de embargar los bienes del Estado en caso de incumplimiento, es así que frente a esto, el ciudadano se encuentra indefenso aun teniendo una sentencia que le otorga un derecho. De allí, que las sentencias proferidas por la Corte IDH gozan de efectividad declarativa, mas no de efectividad en su ejecución, pues ésta queda a disposición de la buena fe del Estado.

Es en este punto donde el Sistema Interamericano está en deuda al no garantizar el cumplimiento de lo decidido, ya que el verdadero valor de una sentencia se demuestra a la hora de su ejecución, donde se hace efectiva la decisión. Así, acatar las sentencias implica someterse a las reglas de derecho internacional y se convierte en el acto más importante de protección efectiva de los Derechos Humanos.

El Sistema no garantiza la ejecución de las sentencias, no obstante cuenta, como se vio, con formas de supervisión fundamentadas en la buena fe de los Estados, a pesar de ello se observa que Venezuela sigue incumpliendo con las obligaciones contraídas en el Tratado al declarar inejecutables varias sentencias proferidas por la Corte IDH. Adquiriendo total validez lo dicho por el jurista Gonzales, al concluir que: "en la práctica la Asamblea General de la OEA no ha dotado de eficacia el artículo 65 de la Convención Americana, que le asigna un rol en el cumplimiento de las sentencias de la Corte Interamericana. A lo sumo, su función se ha circunscrito a declaraciones de carácter general, como cuando se ha planteado de manera genérica que se lleve a cabo dicho cumplimiento. Ha sido la propia Corte la que se ha encargado de esta tarea, con las limitaciones prácticas

88 Convención Americana de Derechos Humanos, 1969, artículo 68.2. 
que limitan su labor al respecto" 89 . Dejándose claro que de seguir así, el sistema corre el riesgo de perder credibilidad al convertirse en un órgano jurisdiccional meramente declarativo que no puede hacer nada ante el incumplimiento de los obligados por parte del Tratado.

\section{CONClusiones}

La obligatoriedad del sistema interamericano está dada por el principio de pacta sunt servanda, según el cual "todo tratado en vigor obliga a las partes y debe ser cumplido por ellas de buena fe" 90 . En consecuencia, al establecer los instrumentos que regirían el sistema, no se observó la necesidad de consagrar sanciones en contra de los Estados incumplidos, partiendo de la confianza legítima que actuarían de buena fe en el cumplimiento de los compromisos adquiridos.

Los sistemas de supervisión al cumplimiento de las sentencias de la Corte son tanto el informe anual que se presenta ante la Asamblea General de la OEA, como las resoluciones de cumplimiento que se emiten después del fallo. Sin embargo, estos mecanismos son inocuos, al no contemplar medidas coercitivas frente al incumplimiento, ya que el informe que se presenta anualmente ante la Asamblea no representa ninguna sanción, ni siquiera es discutido por los países miembros para decidir al respecto; y en lo concerniente a las resoluciones de cumplimiento que se emiten después de la sentencia, se han convertido en una simple insistencia a acatar el fallo, por lo tanto, podemos afirmar que estos mecanismos resultan insuficientes al carecer de medida sancionatoria que obligue al cumplimiento de la misma.

La Convención Americana constituye a la Corte como máximo intérprete del Tratado y de su jurisprudencia, a pesar de ello, la Sala Constitucional del Tribunal Supremo de Justicia argumentando que por encima de éste "no existe órgano jurisdiccional alguno" 91 decidió interpretar el contenido y alcance de las sentencias proferidas por la Corte IDH, declarándolas inejecutables, desconociendo así las normas del Tratado.

Para el órgano de cierre constitucional, las sentencias emanadas del tribunal transnacional representan una violación del ordenamiento jurídico venezolano, aduciendo que los Tratados internacionales sobre Derechos Humanos no tienen

89 GonZÁlez (2012), pp. 150-151.

90 Convención de Viena sobre el Derecho de los Tratados, 1969, artículo 26.

91 Sala Constitucional del Tribunal Supremo de Justicia Venezolano. Sentencia 1942, de 15 de julio de 2003. 
rango supraconstitucional y que al ejecutarse lo fallado no puede pugnar con las normas internas, por lo que la sentencia resultaría inejecutable.

Sin embargo, carece de validez tal argumento, ya que a la luz de lo consagrado en el artículo 23 de la Constitución venezolana, las normas de los Tratados sobre Derechos Humanos prevalecen en el orden interno, siempre y cuando contengan normas más favorables respecto a su goce y ejercicio, de conformidad con ello las disposiciones del Tratado son de aplicación "inmediata” según la misma Constitución y no puede alegarse violación de la norma constitucional, frente a la ejecución de una sentencia emanada del Tratado.

La afectación del proyecto político de la nación venezolana y la transgresión de su soberanía, es otro argumento para declarar inejecutable las sentencias de la Corte IDH. Para la Sala, las mismas colisionan con su soberanía, pues considera que mientras existan Estados soberanos, la ejecución de las sentencias de organismos internacionales deberá estar conforme a la Constitución, que no sólo comprende las normas de carácter positivo, sino su fundamento axiológico representado en el proyecto político del Estado venezolano.

Resultan infundados los argumentos por dos razones, primero por desconocer lo que en la actualidad representa el concepto de soberanía, que se relativiza para dar cabida a la relación con otros Estados así como al cumplimiento del compromiso de aplicar las sentencias proferidas por los organismos internacionales; $y$ segundo, porque con ello se termina desconociendo la soberanía que le permitió al Estado venezolano firmar y comprometerse con el Tratado. Además, de acuerdo con el artículo 27 de la Convención de Viena resulta inadmisible que una parte invoque las disposiciones de su derecho interno a fin de incumplir el Tratado.

En conclusión, la competencia que a motu proprio se adjudicó la Sala Constitucional del Tribunal Supremo de Justicia y los argumentos jurídicos alegados para no acatar las sentencias de la Corte IDH, carecen de fundamento y constituyen una violación a las obligaciones que en virtud de la Convención asumió Venezuela, cuando reconoció la competencia contenciosa de la Corte. Además, desconociendo que una vez decretadas las sentencias constituyen cosa juzgada que sólo pueden ser interpretadas por la misma instancia que la profirió.

\section{BibLIOGRAFÍA CITADA}

Aguiar, Asdrúbal (1994): "La responsabilidad internacional del Estado por violación de Derechos Humanos (apreciaciones sobre el Pacto San José)”, Revista de Derecho Público (Nos. 53-54), pp. 5-31. 
Ayala Corao, Carlos (2007): "La ejecución de sentencias de la Corte Interamericana de Derechos Humanos", Estudios Constitucionales (Año 5, No 1), pp. 127-201.

BosCÁN, Guillermo (2007): "El poder político de los tribunales constitucionales y su incidencia sobre la calidad de la democracia. El caso de la Sala Constitucional del Tribunal Supremo de Justicia venezolano", Revista de Ciencias Jurídicas de la Universidad Rafael Urdaneta (Vol. I, No 1), pp. 1-68.

BREWER-CARÍAS, Allan R. (2012): "El ilegítimo 'control de constitucionalidad' de las sentencias de la Corte Interamericana de Derechos humanos por parte de la Sala Constitucional del Tribunal Supremo de Justicia de Venezuela: el caso Leopoldo López vs. Venezuela, septiembre 2011”, Anuario Iberoamericano de Justicia Constitucional (núm. 16), pp. 355-387.

BREWER-CARíAs, Allan R. (2007): "Alcance y sentido de las propuestas (conocidas) de reformas a la Constitución de 1999 (junio 2007) hacia un Estado Socialista, Centralizado y Policial". [Fecha de consulta: 13 de mayo de 2017]. [Disponibles en: http://allanbrewercarias.net/Content/449725d9-f1cb-474b-8ab2-41efb849fea3/Content/Alcance\%20y\%20Sentido\%20de\%20las\%20Propuestas $\% 20$ de\%20Reforma\%20Constitucional\%20Julio\%202007\%20[1].pdf].

Cançado Trindade, Antonio A. (2000): "Informe del Presidente de la Corte Interamericana de Derechos Humanos a la Comisión de Asuntos Jurídicos y Políticos (CAJP) del Consejo Permanente de la Organización de los Estados Americanos (OEA) (16 de marzo de 2000)", [fecha de consulta: 13 de mayo de 2017]. [Disponible en: https://archivos.juridicas.unam.mx/www/bjv/ libros/5/2193/7.pdf].

Cantón, Santiago (2013): "Los cuatro pilares del Sistema Interamericano de Derechos Humanos y los debates sobre su fortalecimiento", Pensamiento propio (Buenos Aires Argentina, Coordinadora Regional de Investigaciones Económicas y Sociales-CRIES), pp. 255-285.

CÁrdenas Velásquez, Byron Guadalupe (2015): "El problema de la 'eficacia interna' de las declaraciones de incompatibilidad normativa”, Tesis doctoral el control de las normas internas en la jurisprudencia del Tribunal Europeo de Derechos Humanos y la Corte Interamericana de Derechos Humanos: especial consideración del caso España y Nicaragua (Barcelona, Universidad Autónoma de Barcelona), pp. 297-312.

Carrillo Artiles, Carlos Luis (2005): "La asunción jurisprudencial de la interpretación constitucional por la Sala Constitucional del Tribunal Supremo de Justicia venezolano", Universidad Central de Venezuela, Instituto de Derecho 
Público, El Estado constitucional y el derecho administrativo en Venezuela: libro homenaje a Tomás Polanco Alcántara (Caracas, Instituto de Derecho Público UCV y Fundaciones Estudios de Derecho Administrativo Funeda).

Carrillo Salcedo, Juan Antonio (1969): Soberania del Estado y Derecho Internacional (Madrid, Editorial Tecnos).

Cú́llar, Roberto y SaAvedra, Pablo (2010): Diálogo Jurisprudencial: Derecho internacional de los derechos humanos, Tribunales Nacionales, Corte Interamericana de Derechos Humanos No 8 (México, Editorial de servicios especiales-IIDH).

Faúndez Ledesma, Héctor (2004): "El Sistema Interamericano de protección de Derechos Humanos", tercera edición (San José, Costa Rica, IIDH-Instituto Interamericano de Derechos Humanos).

García RAmírez, Sergio (2002): "El acceso de la víctima a la Jurisdicción Internacional sobre Derechos Humanos", Revista Instituto Interamericano de Derechos Humanos (Vol. 32-33), pp. 223-270.

Gonzales Morales, Felipe (2012): Tesis Doctoral las transformaciones del Sistema Interamericano de Derechos Humanos durante los procesos de democratización de los Estados Partes (Getafe, Instituto de Derechos Humanos Bartolomé de las Casas).

Hernández G., José Ignacio (2016): "Justicia constitucional y poder político en Venezuela", Nadya Hernández, Anuario de Derecho Constitucional Latinoamericano año XXII (Bogotá, Fundación Konrad Adenauer Stiftung), pp. 75-95.

Human Rights Watch (2008): Una Década de Chávez. Intolerancia política y oportunidades perdidas para el progreso de los derechos humanos en Venezuela (New York, Human Rights Watch).

Márquez LuZardo, Carmen María (2014): "La denuncia de la Convención Americana sobre Derechos Humanos y otros casos paradigmáticos. Los precedentes de: Trinidad y Tobago; Perú y Venezuela", Revista de Ciencias Jurídicas de la Universidad Rafael Urdaneta (Vol. VIII, No 1), pp. 27-56.

Meier García, Eduardo (2011): "Nacionalismo constitucional y Derecho internacional de los derechos humanos", Revista de Estudios Constitucionales (Vol. 9, No 2), pp. 329-376.

Naranjo Mesa, Vladimiro (2003): Teoría constitucional e instituciones políticas, novena edición (Bogotá, Editorial Temis S.A.).

Pellegrini, Lisandro (2010): "Incumplimiento de las sentencias de la Corte Interamericana de Derechos Humanos", Gisela Elsner, Sistema Interamericano de Protección de los Derechos Humanos y Derecho Penal Internacional (Montevideo, Konrad-Adenauer-Stiftung), pp. 81-102. 
RamíreZ, Blas Eduardo (2013): "El Derecho a la Tutela Judicial Efectiva en el Derecho Procesal Paraguayo", [fecha de consulta: 6 de junio de 2016]. [Disponible en: https://www.researchgate.net/publication/237583168_El_ derecho_a_la_tutela_judicial_efectiva (https://www.researchgate.net/publication/237583168_El_derecho_a_la_tutela_judicial_efectiva)].

\section{NORMAS JURÍDICAS CITADAS}

Acta Final de la V Reunión de Consulta de Ministros de Relaciones Exteriores, 18 de agosto de 1959.

Constitución de la República Bolivariana de Venezuela. Gaceta Oficial No 36.860, 30 de diciembre de 1999.

Convención Americana sobre Derechos Humanos-CADH (Pacto de San José), 22 de noviembre de 1969.

Convención de Viena sobre el Derecho de los Tratados, 23 de mayo de 1969.

Convenio Europeo de Derechos Humanos. Boletín Oficial del Estado No 243, 4 de noviembre de 1950.

Estatuto de la Corte Interamericano de Derechos Humanos. Resolución No 448, octubre de 1969.

Ley aprobatoria de la Convención Americana. Gaceta Oficial No 31256, 14 de junio de 1977.

Ley Orgánica del Tribunal Supremo de Justicia. Gaceta Oficial No 37.942, 20 de mayo de 2004.

Reglamento del Consejo Permanente de la OEA, 1 de octubre de 1980.

Reglamento de la Corte Interamericana de Derechos Humanos, 25 de noviembre de 2001.

\section{JURISPRUDENCIA CITADA}

Servio Tulio León Briceño (2000): Sala Constitucional del Tribunal Supremo de Justicia, 22 septiembre 2000 (recurso de interpretación) en Reportes de decisiones Tribunal Supremo de Justicia No 1077.

Hermann Escarrá (2001): Tribunal Supremo de Justicia, 19 julio 2001(recurso de interpretación) en Reportes de decisiones Tribunal Supremo de Justicia No 1309.

Harry Gutiérrez y Johbing Richard (2003): Sala Constitucional de Tribunal Supremo de Justicia, 22 enero 2003 (solicitud de interpretación constitucional) en Reportes de decisiones Tribunal Supremo de Justicia No 23. 
Rafael Chavero Gazdik (2003): Sala Constitucional del Tribunal Supremo de Justicia, 15 julio 2003 (acción de nulidad por inconstitucionalidad) en Reportes de decisiones Tribunal Supremo de Justicia No 1942.

Julio Borges y otros (2004): Sala Electoral del Tribunal Supremo de Justicia, 15 marzo 2004 (Recurso Contencioso Electoral conjuntamente con solicitud de amparo cautelar) en Revista Ius et Praxis (2004), (Vol. 10, No 1), pp. 361-382.

Ismael García (2004): Sala Constitucional del Tribunal Supremo de Justicia, 23 marzo 2004 (revisión de la sentencia No 24) en Revista Ius et Praxis (2004), (Vol. 10, No 1), pp. 383-396.

Pedro Colmenares Gómez (2006): Sala Constitucional del Tribunal Supremo de Justicia, 27 julio 2006 (acción de amparo) en Reportes de decisiones Tribunal Supremo de Justicia No 1461.

Ziomara del Socorro Lucena Guédez (2008): Sala Constitucional de Tribunal Supremo de Justicia, 5 agosto 2008 (recurso de nulidad) en Reportes de decisiones Tribunal Supremo de Justicia No 1265.

Abogados Gustavo Álvarez Arias y otros (2008): Sala Constitucional de Tribunal Supremo de Justicia, 18 diciembre 2008 (recurso de interpretación) en Reportes de decisiones Tribunal Supremo de Justicia No 1939.

Mejía Idrovo vs. Ecuador (2011): Corte Interamericana de Derechos Humanos, 5 julio 2011 (Excepciones Preliminares, Fondo, Reparaciones y Costas) en Jurisprudencia Corte Interamericana de Derechos Humanos serie No 228.

Carlos Escarrá Malavé y otros (2011): Sala Constitucional del Tribunal Supremo de Justicia, 17 octubre 2011 (acción innominada de control de constitucionalidad) en Reportes de decisiones Tribunal Supremo de Justicia No 1547.

Gelman vs. Uruguay (2013): Resolución de la Corte Interamericana de Derechos Humanos, 20 de marzo de 2013 (supervisión de cumplimiento) en supervisión de cumplimiento de la sentencia Corte Interamericana de Derechos Humanos. Viceprocurador General de la República (2015): Sala Constitucional del Tribunal Supremo de Justicia, 20 febrero 2015 (demanda de interpretación constitucional) en Reportes de decisiones Tribunal Supremo de Justicia No 100.

Reinaldo Enrique Muñoz Pedroza y otros (2015): Sala Constitucional del Tribunal Supremo de Justicia, 22 junio 2015 (acción de control convencionalidad) en Reportes de decisiones Tribunal Supremo de Justicia No 1175. 